\title{
INTERFACE MORFOLOGIA-FONOLOGIA: TEORIAS, ABORDAGENS E TEMAS
}

\author{
Carlos Alexandre Gonçalves
}

\begin{abstract}
RESUMO
Neste artigo, descrevemos os modelos teóricos para o tratamento da interface morfologia-fonologia na linguística contemporânea até o advento da teoria da otimalidade, no início da década de 1990. Ao focalizar a diferença entre as propostas uni e bilaterais de interação desses dois níveis, apresentamos alguns fenômenos do português que podem ser abordados nessa interface.
\end{abstract}

PALAVRAS-CHAVE: morfologia; fonologia; interface.

\section{Palavras iniciais}

ão dois os principais objetivos deste texto: (a) fazer uma breve retrospectiva dos enfoques sobre a interação da morfologia com a fonologia na linguística contemporânea pré-otimalista (inícios dos anos 1990) e (b) apresentar alguns fenômenos do português que podem ser descritos nessa interface. Com ênfase na descrição de dois modelos sobre a interface em foco, a fonologia lexical e a morfologia prosódica, procuramos abordar as formas de interação dos processos morfológicos com os fonológicos.

\section{Retrospectiva dos estudos sobre interface morfologia-fonologia}

Como mostra Gussmann $(1985)^{1}$, a consciência de que a morfologia e a fonologia estão interconectadas de várias maneiras sempre esteve presente

1 GUSSMANN, E. Phono-morphology: Studies in the interaction of phonology and morphology. Lublin: University of Lubeskiego, 1985. 
na linguística pós-saussureana. Obviamente, o modo como essa interação é concebida varia não apenas em função do conceito de gramática adotado, mas também conforme o aporte teórico utilizado. Por exemplo, o estruturalismo americano de orientação bloomfieldiana encarou a relação como unidirecional, pressupondo que os resultados da análise fonêmica determinam a maior parte da morfologia das línguas naturais (cf., p. ex., JOOS, 1957) ${ }^{2}$. A figura em (01), a seguir, representa bem as ideias desse grupo de linguistas, que acreditava ser a análise morfêmica reflexo da fonêmica: a morfologia é vista como uma espécie de imagem em espelho da fonologia.

Figura 1: Representação da relação morfologia-fonologia no Estruturalismo

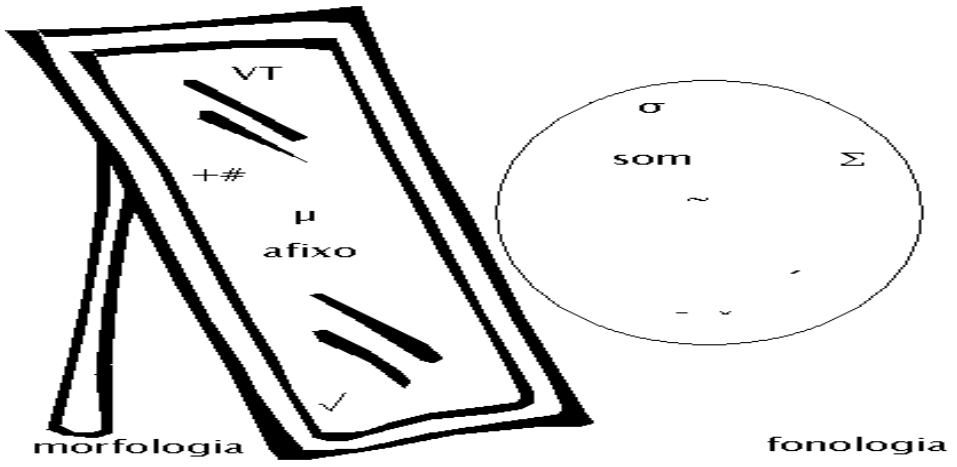

(01)

Um fenômeno de análise morfológica que recebeu destaque no estruturalismo linguístico foi a alomorfia. Definida como uma alteração na conformação física de morfemas, a alomorfia envolve distúrbio no ideal de univocidade entre forma e conteúdo, pois o morfema (entidade do plano do conteúdo) pode aparecer representado por formas diferentes, perspectiva na qual os chamados alomorfes constituem as representaçóes fonéticas divergentes (variaçóes) de um mesmo morfema. Como a maior parte das alteraçóes nos constituintes morfológicos apresenta explicação segmental, especial ênfase foi dada às mudanças no sistema fonêmico do vocábulo com repercussão no sistema mórfico.

2 JOOS, M. Readings in Linguistics I: The Development of Descriptive Linguistics in America since 1925. Washington: ACLS, 1957. 
Há alomorfia condicionada fonologicamente em praticamente todos os elementos morfológicos do português: prefixos, sufixos, vogais temáticas, desinências verbais, desinências nominais e radicais, como se observa nos exemplos a seguir, respectivamente:

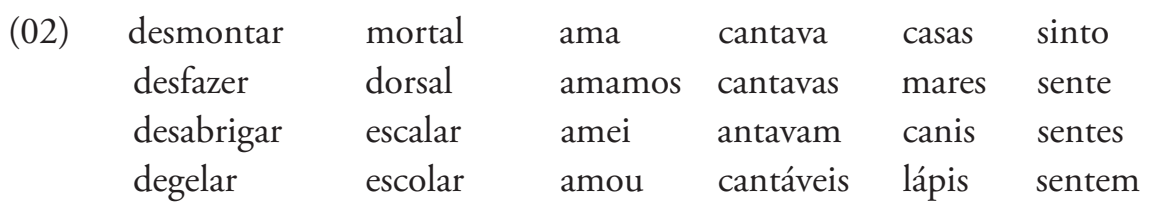

Nos dados em (02), observa-se, na primeira coluna, alomorfia no prefixo que indica reversibilidade, pois sua consoante final alterna, na posição de coda, entre surda ('desfazer') e sonora ('desmontar') ou se realiza com alveolar vozeada em onset da sílaba seguinte ('desabrigar'), podendo, ainda, sofrer apagamento em contato com sibilantes ('degelar', 'dessalgar', 'dessecar'). Na segunda coluna, a realização do sufixo modal que forma adjetivos a partir de substantivos é condicionada pela existência de /// no onset da sílaba final: quando essa sílaba apresenta uma lateral, o sufixo se manifesta $\{$-ar\}, a exemplo de 'escalar', 'escolar' e 'milenar'. Nos demais casos, a consoante do sufixo se realiza como líquida lateral (p. ex., 'vital', 'mortal', 'constitucional'). Na terceira, a vogal temática de primeira conjugação não se realiza como /a/ em todas as pessoas, já que assimila a altura e a zona de articulação da vogal seguinte, a marca morfológica de número/pessoa. Na quarta coluna, o elemento que expressa tempo/modo alterna entre /va-/ e /ve-/, sendo a última realização determinada pela vogal alta que inicia o elemento responsável pela informação de $\mathrm{P} 5$, a desinência $\{$-is $\}$.

No caso do plural, a anexação do $\{-S\}$ pode levar a uma série de modificaçôes fonológicas: desde a epêntese vocálica em palavras terminadas em consoantes ('mares') até o apagamento de líquidas laterais ('canis') e a degeminação das sibilantes finais ('lápis'). Por fim, a raiz de 'sentir' pode ter sua vogal realizada como alta por metafonia, ou seja, por influência da vogal alta que manifesta P1.

Dados de alomorfia como os apresentados em (02) dáo mostras de que a constituição segmental da palavra repercute na realização dos elementos morfológicos, o que levou os estruturalistas à interpretaçâo unilateral da interface 
morfologia-fonologia. Pike e seus discípulos, por outro lado, nunca endossaram a hipótese da unidirecionalidade estrita, insistindo, ao contrário, na necessidade de reconhecer os "pré-requisitos gramaticais da análise fonêmica" (PIKE, 1947: 39)3 , numa clara alusão de que a morfologia também poderia repercutir na fonologia.

O desenvolvimento da gramática transformacional e, em particular, do modelo clássico de fonologia gerativa (CHOMSKY \& HALLE, 1968) ${ }^{4}$ mudou radicalmente o entendimento da relação morfologia-fonologia, assinalando a relevância das alteraçóes morfofonêmicas no estabelecimento de regularidades fonológicas. Como resultado, a morfologia interessante à análise fonológica passou a ser formalizada, nas regras fonológicas que se aplicam a representaçóes subjacentes abstratas, por símbolos de fronteira, deixando de existir um componente morfológico autônomo. Pode-se afirmar, com isso, que especial destaque foi dado ao efeito do condicionamento morfológico das operaçóes fonológicas, perspectiva diametralmente oposta à assumida pela maior parte dos estruturalistas. Por exemplo, observa-se, nos dados em (03), a seguir, que uma nasal alveolar ([n]) se desenvolve quando, numa fronteira morfológica, o sufixo se inicia por vogal.

$$
\begin{array}{lll}
\text { fim }>\text { final } & \text { rã }>\text { ranário } & \text { bom }>\text { boníssimo } \\
\text { um }>\text { único } & \text { ordem }>\text { ordenar } & \text { som }>\text { sonoro }
\end{array}
$$

Uma regra fonológica pode ser proposta para representar os dados em (03). Essa regra, no entanto, tem de fazer referência à fronteira de morfemas (representada por + ), pois náo se aplica entre palavras, como se observa pela agramaticalidade de realizaçóes como ${ }^{*}$ irmanamiga ou *ranágil. Assumindo que as bases apresentam uma nasal não especificada para ponto $(/ \mathrm{N} /)$ na posição de coda silábica, pode-se propor a regra fonológica em (04), que traz a nasal à superfície, atualizando-a como coronal, [n], numa fronteira de morfemas (+), quando o segmento seguinte é uma vogal:

3 PIKE, K. L. Phonemics: A technique for reducing languages to writing. Ann Arbor, MI: University of Michigan, 1974.

4 CHOMSKY, N.; HALLE, M. The sound pattern of English. New York: Harper and Row, 1968. 
(04)

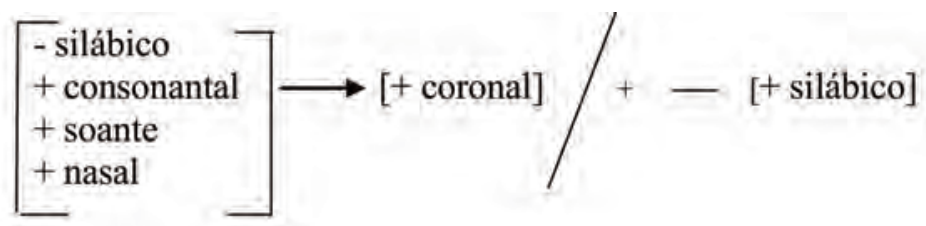

$\mathrm{Na}$ década de 1970, iniciou-se um movimento de reação não apenas contra a extrema abstração das descrições gerativistas baseadas em SPE (The Sound Pattern of English), mas também contra a falta de distinção entre regras fonologicamente condicionadas e regras morfologicamente condicionadas, o que deu origem a várias revisóes do modelo clássico de fonologia gerativa, amplamente denominadas de "naturais". No entanto, como mostra Booij $(1985)^{\bigotimes}$, nenhuma generalização relevante foi alcançada em relação à interface morfologia-fonologia na fonologia gerativa natural - nem no trabalho de Hooper $(1976)^{5}$ nem no de Dressler $(1977)^{6}$.

Após um período de abandono inicial, a morfologia derivacional assistiu a importantes desenvolvimentos em meados de 1970, a partir do trabalho de Chomsky $(1970)^{7}$. Pela primeira vez na história da teoria gerativa, postulou-se um componente morfológico autônomo, independente do sintático ou do fonológico. Logo após, Halle $(1973)^{8}$ investigou com mais vagar os princípios que regem a estrutura das palavras, propondo um novo módulo à gramática: o componente 'formação de palavras', localizado no léxico.

Desse modo, Chomsky $(1970)^{8}$ e Halle $(1973)^{9}$ atribuíram ao léxico uma estrutura mais refinada, contribuindo, decisivamente, para uma tomada de consciência sobre o papel desse componente na teoria linguística de inflexão gerativista. A partir daí, vários autores dedicaram-se ao estudo da

5 HOOPER, J. B. Word frequency in lexical diffusion and the source of morphophonological change. In Christie, W. (ed.) Current Progress in Historical Linguistics. Amsterdam: North Holland, p. 96-105, 1976.

6 DRESSLER, W. Elements of a polycentristic theory of word formation. Wiener Linguistische Gazette, 15, 13-32, 1977.

7 CHOMSKY, N. Remarks on Nominalization. In: JACOBS, R. and ROSENBAUM, P. (eds.). Readings in English Transformational Grammar. Ginn, Waltham: MA, 184-221, 1970 .

8 HALLE M. Prolegomena to theory of word formation. Linguistic Inquiry, 4, 3-16, 1973. 
organização do léxico e das regras que caracterizam a estrutura das palavras, como, entre tantos outros, Siegel $(1974)^{9}$, Aronoff $(1976)^{10}$ e Lieber $(1980)^{11}$. Siegel $(1974)^{10}$, por exemplo, defendeu que o léxico também poderia ser usado para expressar processos fonológicos. Como observa Mohanan (1986: 5) ${ }^{12}$, estávamos, nessa época, diante de um movimento intelectual em favor de um componente lexical mais robusto.

Os chamados modelos de morfologia lexical produziram nova dimensão para a interface morfologia-fonologia, pois evidenciaram que regras de formação de palavras podem requerer acesso à informação fonológica, do mesmo modo que regras fonológicas podem ser de algum modo condicionadas pela morfologia derivacional (SZYMANEK, 1980) ${ }^{13}$. Exemplifiquemos, com dados do português, cada uma das situaçóes acima comentadas. No primeiro caso, formas com alternância entre -ar e -al, já referenciadas, revelam que há restrições sobre a sílaba resultante do encadeamento morfológico.

Nas formaçóes X-al, o sufixo é silabificado com a raiz à qual se adjunge. No entanto, isso não significa que a fronteira morfológica da palavra seja respeitada pela fonologia, pois não necessariamente coincide com a fronteira silábica, não havendo, portanto, isomorfismo entre estruturas morfológicas e prosódicas: o sufixo forma sílaba com a última consoante da base. A regra de formação de adjetivos a partir de substantivos acessa informaçóes sobre o último segmento da base, promovendo a automática substituição da coda final por uma vibrante quando o raiz termina numa lateral alveolar (cavalo > cavalar; família $>$ familiar, tutela $>$ tutelar), num claro processo de dissimilação.

Regras fonológicas são também condicionadas pela morfologia derivacional e um bom exemplo dessa situação em português é a neutralização das pretônicas. Como se sabe, perde-se a oposição entre as médias nesse ambiente em favor de realizaçóes defaults mais fechadas na fala carioca (CÂMARA JR., $1970)^{14}$. Apesar de bastante geral, essa regra não se aplica no ambiente de sufixos

9 SIEGEL, D. Topics in English Morphology. Massachusetts: The MIT Press, 1974.

10 ARONOFF, M. Word formation in generative grammar. Massachusetts: The MIT Press, 1976.

11 LIEBER, R. On the organization of the lexicon. New Jersey: IULC, 1980.

12 MOHANAN, K. P. The theory of lexical phonology. Dordrecht, Holland: Reidel, 1986.

13 SZYMANEK, B. Phonological conditioning of word formation rules. Folia Linguistica 14: 413-425, 1980.

14 CÂMARA JR., J. M. Estrutura da língua portuguesa. Petrópolis: Vozes, 1970. 
não-coerentes (BOOIJ, 2005) ${ }^{14}$, como -mente e -(z)inho, diferentes dos demais por preservarem a integridade fônica das bases. Nos dados a seguir, contrastam-se formas derivadas em que a neutralização se aplica (primeira coluna) com formas em que esse processo não tem vez (segunda coluna), o que reforça a tese de que a fonologia é sensível a informações morfológicas:

$$
\begin{array}{ll}
\text { belo }>\text { beleza } & \text { certo }>\text { certinho } \\
\text { mel }>\text { melado } & \text { veloz }>\text { velozmente } \\
\text { vela }>\text { veleiro } & \text { chapéu }>\text { chapeuzinho } \\
\text { bola }>\text { bolada } & \text { bola }>\text { bolinha } \\
\text { cola }>\text { colar } & \text { alegre }>\text { alegremente }
\end{array}
$$

Apesar dos inegáveis desenvolvimentos, os vários modelos de morfologia lexical continuaram defendendo a separação entre a morfologia e a fonologia. As regras do componente morfológico aplicam-se em primeiro lugar, dando origem às estruturas das palavras que, depois de modificadas pelas regras de (re)ajustamento, constituem o input para o componente fonológico. Nos termos de Ferreira (2009: 39) $)^{15}$, os dois módulos "estão separados porque os processos morfológicos se referem à fonologia num sentido muito limitado, i.e., apenas acedem à informação fonológica presente na estrutura subjacente das palavras". De acordo com Szpyra (1989: 11) ${ }^{16}$, assume-se, nesses vários movimentos, que uma análise morfológica adequada constitui pré-requisito para uma descrição fonológica apropriada. Contudo, apesar dessa constatação, a prática fonológica continuou recorrendo pouco ou nada à morfologia.

\section{A fonologia lexical}

Foi na década de 1980, no entanto, que surgiu um modelo de análise linguística especificamente voltado para a interação das representaçôes fonológicas com as estruturas morfológicas (e vice-versa). As relaçôes entre morfologia e fonologia constituem o cerne da chamada fonologia lexical (KIPARSKY,

15 FERREIRA, A. S. S. R. Flexão de número dos nomes terminados em ditongo nasal à luz da fonologia lexical. Dissertação (Mestrado em Linguística). Porto: Universidade do Porto, 2009.

16 SZPYRA, J. The phonology-morphology interface: cycles, levels and words. London: Routledge, 1989. 
1982 ${ }^{17}$; MOHANAN, 1982 ${ }^{18}$; BOOIJ \& RUBACH, 1984 ${ }^{19}$ ), abordagem que fornece alternativas analíticas interessantes para a descrição das variaçóes morfológicas e morfofonêmicas, ao dividir a língua em estratos nos quais se aplicam regras de formação de palavras (derivação, flexão e composição) e regras fonológicas.

A fonologia lexical pode ser considerada, como aponta Mohanan (1986: $05)^{20}$, uma extensão da tendência lexicalista à fonologia. Desse modo, o destaque ao componente morfológico e a concepção de que o léxico não é um apenas um lugar para os fora-da-lei ou um depositário de idiossincrasias constituem a linha de frente desse modelo, que surge como consequência natural da hipótese lexicalista de Chomsky $(1970)^{21}$ e da morfologia lexical, desenvolvida, sobretudo, por Aronoff (1976) 22 .

$\mathrm{O}$ aspecto central do modelo é a existência de dois componentes - o lexical e o pós-lexical -, espelhando a dicotomia existente entre a estrutura da palavra e a da frase (MOHANAN, 1986:5)22. No módulo lexical, operam regras morfológicas em interação com regras fonológicas. No pós-lexical, que envolve domínios maiores que a palavra, aplicam-se regras fonológicas posteriores aos processos sintáticos. Da relação entre processos morfológicos e operações fonológicas, resultam representações lexicais (i. e. representações fonológicas de palavras geradas pelo léxico) distintas da representação subjacente. Desse modo, para além dos níveis de representação preconizados pela fonologia gerativa standard, a divisão da gramática nos componentes lexical e pós-lexical pressupóe a existência de mais um tipo de representação: a lexical (MOHANAN, 1986:10) ${ }^{22}$.

Tal como a fonologia estruturalista, a fonologia lexical reconhece a existência de um nível de representação intermediário, o morfofonêmico. No en-

17 KIPARSKY, P. From cyclic phonology to lexical phonology. In: HULST, H.; SMITH, N. (org.). The structure of phonological representations (Parte 1). Dordrecht: Foris, p. 131-176, 1982.

18 MOHANAN, K. P. Lexical Phonology. Massachusetts: MIT, 1982.

19 BOOIJ, G. \& RUBACH, J. Morphological and prosodic domains in lexical phonology. Phonology Yearbook, n. 1, p. 1-27, 1984.

${ }^{20}$ MOHANAN, K. P. The theory of lexical phonology. Dordrecht, Holland: Reidel, 1986.

${ }^{21}$ CHOMSKY, N. Remarks on Nominalization. In: JACOBS, R. and ROSENBAUM, P. (eds.). Readings in English Transformational Grammar. Ginn, Waltham: MA, 184-221, 1970.

22 ARONOFF, M. Word formation in generative grammar. Massachusetts: The MIT Press, 1976. 
tanto, a fonologia estruturalista não foi capaz de construir uma modelo formal que descrevesse adequadamente esse nível de representação (MOHANAN, 1986:3-6). Tem-se, com a fonologia lexical, finalmente, uma concepção bidirecional da interface morfologia-fonologia:

Figura 2: Relação fonologia-morfologia na fonologia lexical

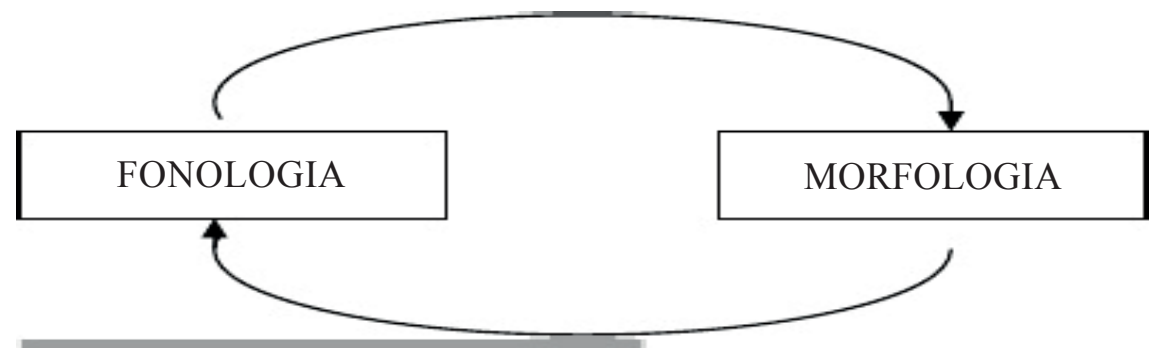

(06)

A fonologia lexical adota o conceito de morfologia ordenada em níveis originalmente encontrado em Siegel $(1974)^{23}$. Para esse autor, o léxico de uma língua está organizado em níveis (ou estratos ordenados) que constituem domínios de aplicação de regras morfológicas e fonológicas que aí encontram a sua descrição estrutural. Essa divisão em estratos é justificada pelo comportamento distinto dos afixos do ponto de vista morfofonológico. Dito de outra maneira, a sensibilidade que afixos despertam em regras fonológicas pode determinar sua alocação em um nível ou outro do léxico. Em Kiparsky (1982) 24, encontra-se a seguinte concepção de gramática:

23 SIEGEL, D. Topics in English Morphology. Massachusetts: The MIT Press, 1974.

24 KIPARSKY, P. From cyclic phonology to lexical phonology. In: HULST, H.; SMITH, N. (org.). The structure of phonological representations (Parte 1). Dordrecht: Foris, p. 131-176, 1982. 
Figura 3: O modelo de fonologia lexical.

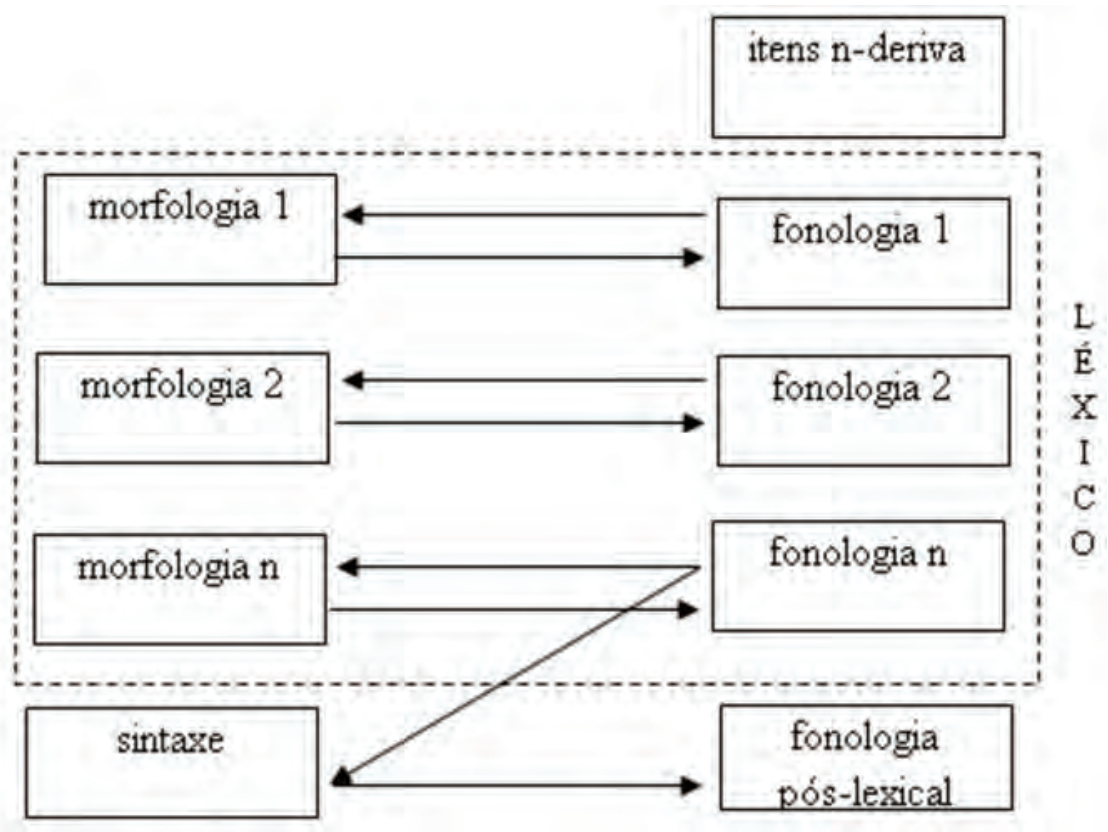

(07)

Uma importante contribuiçãao desse modelo é a postulação de dois principais tipos de regras fonológicas: (a) as lexicais, que, entre outras características, respeitam as informaçóes morfológicas e se aplicam quando a palavra ainda está em formação e (b) as pós-lexicais, totalmente cegas a informações morfológicas e aplicadas apenas quando a palavra já está pronta. O quadro a seguir resume algumas das propriedades das regras lexicais e pós-lexicais (cf. LEE, 1995: 07) 25 :

25 LEE, S. H. Morfologia e fonologia lexical do português do Brasil. Tese de Doutoramento. Campinas: Unicamp, 1995. 
Quadro 1: Diferenças entre regras lexicais e pós-lexicais

\begin{tabular}{|c|c|}
\hline LEXICAIS & PÓS-LEXICAIS \\
\hline $\begin{array}{l}\text { Fazem leitura de rótulos, ou seja, inspe- } \\
\text { cionam a estrutura interna das palavras } \\
\text { (reconhecem formativos); sáo regras } \\
\text { que leem rótulos, não dispensando a } \\
\text { informaçáo contida nos colchetes mor- } \\
\text { fológicos. }\end{array}$ & $\begin{array}{l}\text { São "cegas" à estrutura mórfica das pa- } \\
\text { lavras (não conhecem formativos), não } \\
\text { lendo os rótulos contidos nos colchetes, } \\
\text { pois ignoram tais informaçóes e atraves- } \\
\text { sam fronteiras. }\end{array}$ \\
\hline $\begin{array}{l}\text { Reconhecem categorias lexicais (p. ex., } \\
\text { "sabem" o que é verbo e o que nâo é). }\end{array}$ & $\begin{array}{l}\text { São category blind, ou seja, não reconhe- } \\
\text { cem classes de palavras. }\end{array}$ \\
\hline $\begin{array}{l}\text { Quanto ao domínio de aplicaçáo, não } \\
\text { podem operar fora de palavras (aplica- } \\
\text { çáo intravocabular). }\end{array}$ & $\begin{array}{l}\text { Aplicam-se intra ou extravocabular- } \\
\text {-mente. }\end{array}$ \\
\hline $\begin{array}{l}\text { Podem ser cíclicas (atuar nos vários ci- } \\
\text { clos da derivaçáo) ou não. }\end{array}$ & São necessariamente não-cíclicas. \\
\hline $\begin{array}{l}\text { Preservam estruturas, já que operam } \\
\text { apenas com elementos da representação } \\
\text { subjacente (fonológicos) }\end{array}$ & $\begin{array}{l}\text { Não preservam estruturas, já que po- } \\
\text { dem envolver elementos não-contrasti- } \\
\text { vos (realizaçôes fonéticas). }\end{array}$ \\
\hline $\begin{array}{l}\text { São regras marcadas pela excepcionali- } \\
\text { dade, ou seja, reconhecem exceçóes. }\end{array}$ & $\begin{array}{l}\text { São categóricas (não apresentam exce- } \\
\text { çôes). }\end{array}$ \\
\hline
\end{tabular}
(08)

Exemplo de regra pós-lexical em português é vocalização da lateral palatal, cuja representação informal, bem ao estilo SPE, pode ser feita da seguinte maneira $(/ 1 / \rightarrow[\mathrm{w}] /-\$)$. Tal regra se aplica à palavra pronta, como se vê em (10), não operando em fronteiras morfológicas. Além disso, é categórica e não preserva estrutura, já que /l/ e /w/ não contrastam na posição de coda silábica.

\begin{tabular}{|c|c|c|c|c|}
\hline (09) & & [pa.'p£ w] & & $\begin{array}{l}\text { [pa.pe.'la.de ] } \\
\text { [3 oy na.'le.ru ]) }\end{array}$ \\
\hline
\end{tabular}

Bom exemplo de regra lexical é a assibilação, observada nos dados da primeira coluna em $(10)^{26}$. Nessas formas derivadas, a oclusiva final da base passa

26 LEE, S. H. Morfologia e fonologia lexical do português do Brasil. Tese de Doutoramento. Campinas: Unicamp, 1995. 
a sibilante diante da vogal que inicia o sufixo, uma alta anterior (LEE, 1995). Essa operação fonológica só se aplica no interior de palavras, sendo inoperante na sintaxe, como atestam os dados da segunda coluna:

$\begin{array}{llll}\text { elétrico } & \text { eletri }[\mathrm{s}] \mathrm{idade} & \text { elétrico hidrante } & { }^{*} \text { elétri }[\mathrm{s}] \text { idrante } \\ \text { histórico } & \text { histori }[\mathrm{s}] \text { ismo } & \text { histórico inválido } & { }^{*} \text { histori }[\mathrm{s}] \text { inválido } \\ \text { profeta } & \text { profe }[\mathrm{s}] \mathrm{ia} & \text { profeta inglês } & { }^{*} \text { profe }[\mathrm{s}] \text { inglês } \\ \text { presidente } & \text { presidên }[\mathrm{s}] \text { ia } & \text { presidente inútil } & { }^{*} \text { presiden }[\mathrm{s}] \text { inútil } \\ \text { histórico } & \text { histori }[\mathrm{s}] \mathrm{ice} & \text { fraco irmão } & { }^{*} \text { fra }[\mathrm{s}] \text { irmão } \\ \text { histórico } & \text { histori }[\mathrm{s}] \text { ista } & \text { consciente irmão } & { }^{*} \text { conscien }[\mathrm{s}] \text { irmão }\end{array}$

Os dados em (10) reforçam o ideário básico da fonologia lexical, pois a assibilação, além de duplamente condicionada (pelo segmento seguinte e pela fronteira morfológica), sendo, por isso mesmo, especificada como lexical, é também sensível ao tipo de formativo que atua na fronteira base-afixo, aplicando-se com -ista, -ismo, -ice e -ia, mas deixando de se aplicar com -inho e -íssimo, como se observa, por exemplo, em *fra[s]inho, *profe[s]inha e *ga[s] íssimo. Na perspectiva da fonologia lexical, podemos considerar que (a) os afixos em questão não figuram no mesmo nível do léxico e (b) a regra discrimina diferentes fronteiras de morfema.

Outro exemplo interessante, também relatado por Lee $(1995)^{27}$, é a regra de apagamento de nasal diante de soantes. A formalização feita em (12), a seguir, que acolhe dados como 'ilegal', 'imoral' e 'irreal', formas em que a nasal do prefixo não se manifesta, expressa uma falsa generalização, uma vez que a nasal se mantém em dados como 'enlatar', 'enlutar', 'enredar' e 'enrolar'.
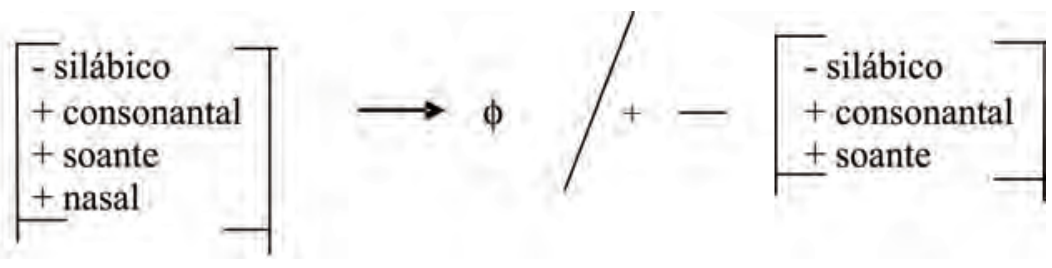

27 LEE, S. H. Morfologia e fonologia lexical do português do Brasil. Tese de Doutoramento. Campinas: Unicamp, 1995. 
O que ocorre, nesses casos, é que o processo fonológico em questão se comporta de modo diferenciado quando atua em processos morfológicos diferentes. Dito de outra maneira, o apagamento de nasal diante de soantes ocorre em casos de derivação prefixal (iN-+real > irreal; iN-+lógico > ilógico), mas não em casos de parassíntese (eN-+raiva+-ecer > enraivecer, *erraivecer; eN-+luto+-ar > enlutar, *elutar). Tal fato revela que os dois processos devem ser alocados em diferentes estratos lexicais, em função, por exemplo, da sensibilidade que despertam à regra de apagamento de nasal.

Como se vê, a fonologia lexical aborda a interface morfologia-fonologia de modo bastante satisfatório, conseguindo preencher uma série de lacunas deixadas nas abordagens precedentes. Apesar disso, não foi capaz de lidar com um tipo de morfologia que sempre se colocou como desafio para vários modelos, de diferentes linhas teóricas: a morfologia não-concatenativa.

\section{A morfologia não-concatenativa e os novos modelos para a interface em tela}

Nos processos aglutinativos, um elemento plenamente especificado remete a algum tipo de significado e é adjungido ou à esquerda ou à direita de outro. Nos não-concatenativos, ao contrário, uma forma de base sofre modificaçôes fonológicas de natureza variada, não havendo, em consequência, estrito encadeamento de elementos morfológicos: o resultado da operação dificilmente leva a uma divisão da palavra em unidades discretas de forma e significado. No quadro em (12) a seguir, adaptado de Gonçalves (2011: $89)^{28}$, apresentamos e exemplificamos os principais tipos de operaçóes não-concatenativas encontradas em português:

28 GONÇALVES, C. A. V. Iniciação aos estudos morfológicos: flexão e derivação em português. São Paulo: Contexto. 
Quadro 2: Os processos não-concatenativos

\begin{tabular}{|l|l|}
\hline \multicolumn{1}{|c|}{ PROCESSO } & \multicolumn{1}{c|}{ DETALHAMENTO E EXEMPLOS } \\
\hline Reduplicação & $\begin{array}{l}\text { Uma palavra (ou parte dela) é redobrada, sendo o material } \\
\text { replicado anexado, posteriormente, à sua esquerda ou à sua } \\
\text { direita: } \\
\text { pega-pega, bate-bate; bololô, chororô, bafafá, trelelê }\end{array}$ \\
\hline Subtração & $\begin{array}{l}\text { Uma forma de base perde um segmento, uma sílaba ou uma } \\
\text { sequência de sons: } \\
\text { mau > má, irmão > irmá; refrigerante > refri, bijuteria > biju; } \\
\text { Alexandre > Alê ou Xande, Heló́sa > Helô }\end{array}$ \\
\hline Cincunfixaçáo & $\begin{array}{l}\text { Um elemento morfológico é dividido em partes para que, em } \\
\text { seu interior, um outro seja anexado: } \\
\text { anoitecer, empobrecer; alargar, enlatar }\end{array}$ \\
\hline Mutação segmental & $\begin{array}{l}\text { Uma alternância vocálica ou consonantal é utilizada com fins } \\
\text { morfológicos, servindo ela mesma como expoente primário } \\
\text { ou secundário de uma categoria gramatical: } \\
\text { Sinto/sente, durmo/dorme; avô/avó, novo/novos }\end{array}$ \\
\hline Fusão & $\begin{array}{l}\text { Duas formas de base se emaranham de tal forma que acabam } \\
\text { compartilhando um ou mais elementos: } \\
\text { chafé, lixeratura, cantriz, boilarina }\end{array}$ \\
\hline Acronímia & $\begin{array}{l}\text { Palavra manufatura normalmente criada a partir das iniciais } \\
\text { de expressóes consituídas de pelo menos duas palavras: } \\
\text { OVNI, CEP, PIS, CIC, CUT }\end{array}$ \\
\hline
\end{tabular}

O português, como as demais línguas indo-européias, apresenta morfologia predominantemente aglutinativa, uma vez que a grande maioria das operações envolve concatenação de afixos ou de radicais. No entanto, há vários processos que não operam com rigoroso encadeamento de formas (GONÇALVES, 2006) ${ }^{29}$. Nesses exemplos, uma forma de base pode adquirir feição fonológica diferente para veicular um conteúdo gramatical, como na flexão verbal, em que mudanças vocálicas são associadas à expressão de número/pessoa ('pude'/'pôde') e modo/tempo/aspecto ('pôde'/'pode'), ou formar nova palavra, como ocorre

29 GONÇALVES, C. A. V. Usos morfológicos: os processos marginais de formação de palavras em português. Gragoatá (UFF), v. 21, p. 219-242, 2006. 
no cruzamento vocabular ('futevôlei', 'sacolé', 'brasiguaio') e na reduplicação ('empurra-empurra', 'pula-pula'), processos a serviço da expansão lexical.

Até a década de 1980, processos como os apresentados em (13) foram deliberadamente deixados à margem das descriçôes morfológicas: não havia como acomodá-los satisfatoriamente em modelos estritamente lineares. Assim, foi graças ao advento das chamadas fonologias não-lineares, como a fonologia autossegmental, a fonologia métrica e a fonologia prosódica, que esses processos saíram da obscuridade e passaram a fazer parte da agenda de trabalho de dois importantes modelos liderados por Jonh McCarthy, da Universidade de Massachusetts Amherst: (1) a morfologia autossegmental (McCARTHY, 1981) $)^{30}$ e (2) a morfologia prosódica (McARTHY, 1986) ${ }^{31}$. Desse modo, a abordagem não linear das representações fonológicas logo repercutiu no campo da morfologia, promovendo a rápida emergência dos estudos sobre as operaçóes não-concatenativas. McCarthy $(1981: 411)^{32}$ assim se posiciona acerca da importância das operaçóes morfológicas não-lineares:

percebemos que o modelo prosódico de morfologia não somente fornece uma descrição reveladora das complexidades do verbo em árabe, mas também fornece uma grande variedade de resultados com relação às propriedades universais de fenômenos de morfologia não-concatenativa.

Em McCarthy $(1981)^{32}$, encontram-se as bases da morfologia autossegmental. Em linhas bem gerais, esse modelo constitui desdobramento natural da fonologia autossegmental, em sua versão apresentada em Goldsmith (1976) ${ }^{32}$. McCarthy $(1981)^{32}$ propóe que mecanismos autossegmentais independentemente motivados - inicialmente usados para o estudo do tom e de outros traços prosódicos - sejam estendidos para o tratamento da morfologia não-concatenativa. Crucial para a proposta é a ideia de que expoentes identificáveis de

30 McCARTHY, J. A prosodic theory of nonconcatenative morphology. Linguistic Inquiry 12, Cambridge, MA, MIT, 1981, p. 373-418.

31 McCARTHY, J. Prosodic morphology. Amherst: University of Massachusetts and Brandeis University, 1986.

32 GOLDSMITH, J. The aims of autosegmental phonology. Bloomington, Indiana, Indiana University Press, 1976. 
categorias morfológicas são separados em diferentes planos ou dimensões de representação. Na sua aplicação da teoria autossegmental à morfologia do árabe, McCarthy (1979) ${ }^{33}$ propóe que uma palavra seja dividida em tiers separados para melodias vocálicas e consonantais, que são linkadas a um template (molde) com informaçóes de posiçôes de vogais e consoantes numa sequência-modelo.

A proposta de Morfologia Autossegmental, feita em McCarthy $(1981)^{34}$, pode ser resumida da seguinte maneira: (i) camadas autônomas de autossegmentos representam diferentes tipos de morfema e se relacionam por linhas de associação que não podem cruzar; (ii) regras podem desligar segmentos do tier $\mathrm{CV}$ e, com isso, promover a realocação do elemento flutuante em outras posiçôes disponíveis no molde; (iii) cada morfema projeta uma camada morfológica própria (hipótese do tier morfêmico); (iv) a ligação dos elementos de uma camada à outra pode ser feita da esquerda para a direita ou da direita para a esquerda, conforme a direcionalidade privilegiada pela língua; e (v) um princípio da gramática, chamado tier conflation, é responsável pela linearização das formas.

Passemos, a seguir, à análise de um fenômeno da morfologia do português que pode ser formalmente expresso com o instrumental fornecido pela morfologia autossegmental, a chamada mutação vocálica (alternância de vogais com fins morfológicos). Para tanto, consideramos, aqui, apenas um padrão: a alternância vocálica que ocorre no pretérito perfeito do indicativo e é o único expoente da informação número-pessoal:

(13) P1: tive, fiz, pude, estive

P3: $\quad$ teve, fez, pode, esteve

De acordo com Gonçalves \& Vivas (2011) $)^{35}$, três tiers independentes são relevantes na representação morfológica do verbo no pretérito perfeito do indicativo. O tier de raiz é responsável por expressar o conteúdo lexical do verbo

33 McCARTHY, J. Formal problems in semitic phonology and morphology. Ph. D. Dissertation, MIT, Cambridge, MA, 1979.

34 McCARTHY, J. A prosodic theory of nonconcatenative morphology. Linguistic Inquiry 12, Cambridge, MA, MIT, 1981, pp. 373-418.

35 GONÇALVES, C. A. V.; VIVAS, V. M. Alternância vocálica na flexão verbal do português: análise pela Morfologia Autossegmental. LinguíStica, 7 (1), junho de 2011, Teoria Fonológica: variação e arquitetura da gramática, p. 79-98, 2011. 
e é plenamente especificado para todos os seus segmentos, exceto para a vogal que se localiza na sílaba tônica, referenciada apenas como [-aberto 1, -aberto 3] e não-especificada para [aberto 2], traço autossegmentalizado, por ser responsável pela informação de pessoa: a definição da vogal da raiz como alta ('fiz', 'pude', 'tive', 'estive') ou média-alta ('fez', 'pode', 'teve', 'esteve') determina se o verbo está na $\mathrm{P} 1$ ou na $\mathrm{P} 3$ e, por isso mesmo, o segmento da raiz não pode ser especificado por [aberto 2], único expoente dessa informação morfológica ${ }^{36}$.

Além dos tiers de raiz e de abertura vocálica, a outra camada autônoma existente é o tier esqueletal, ao qual os demais tiers devem ser linkados. A direção do mapeamento é esquerda-direita; os diferentes segmentos da raiz linkam-se, um a um, ao tier esqueletal. A vogal subespecificada (indicada pelo símbolo V) linka-se, no molde esqueletal, a [aberto 2] da camada de abertura. Ilustramos, abaixo, o modelo de formalização para a alternância vocálica nesse padrão. Aqui, a letra grega $\mu$ representa informação morfológica e a,b,c, segmentos plenamente especificados:

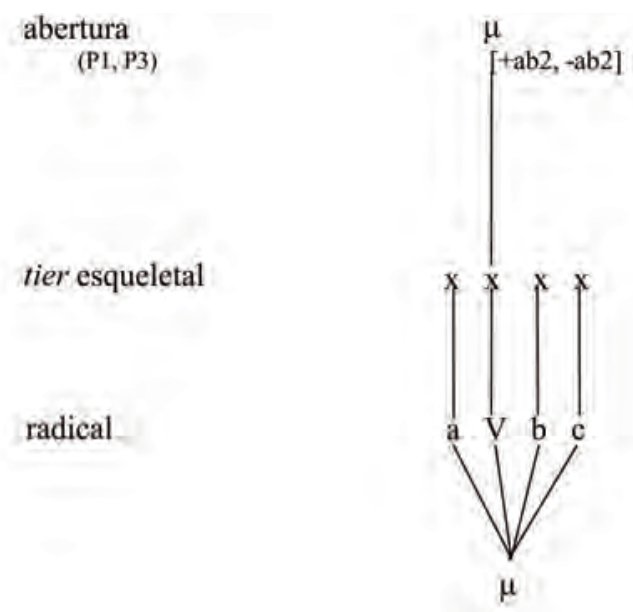

36 Estamos utilizando a proposta de Clements \& Hume (1995) para representar as vogais de nossa língua. Em linhas gerais, o traço [+aberto 1] é responsável por indicar a altura baixa e [-aberto 2] diferencia o nível alto. Para se referir às médias, é preciso observar a ligação de [aberto] na camada 3. Desse modo, verificamos que a altura média-baixa é indicada pelo traço [+aberto 3] e a média-alta, por [-aberto 3].

CLEMENTS, G. N. \& HUME, E. V. "The Internal Organization of Speech Sounds". In: GOLDSMITH, J. A. (ed.). The Handbook of Phonological Theory. Oxford, Blackwell Publishers, pp. 245-306, 1995. 
$\mathrm{Na}$ informação de P1, a vogal, previamente especificada como [-aberto1, -aberto 3], atualiza-se como alta, ligando-se, portanto, a [-aberto 2]. Como demonstrado na formalização a seguir, para 'tive', é a camada de abertura a responsável por manifestar o conteúdo número-pessoal (P1). Posteriormente, é feito o link dos elementos melódicos da raiz às posiçôes de $\mathrm{X}$ no tier esqueletal:

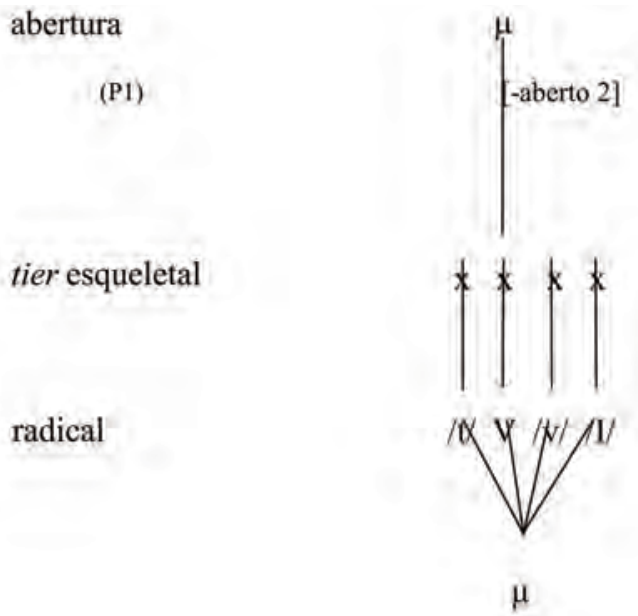

Com a formalização de 'tive', fica evidente que a realização da vogal como alta é o único expoente da informação de P1. Como esse fato também acontece com a vogal posterior ('pude'), confirma-se serem as especificaçóes de local de V ([coronal], [labial], [dorsal]) irrelevantes. A formalização para P3 é semelhante à de P1; a única diferença está na especificação no tier de abertura. Como a vogal média ('teve', 'pode') é o segmento responsável pela informação de P3, a especificação na camada de abertura é [+aberto 2], como ilustramos a seguir, para 'pode': 
(16)

abertura

tier esqueletal

radical

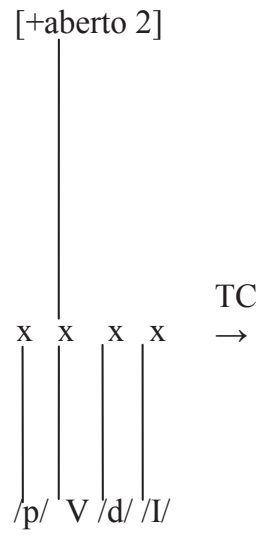

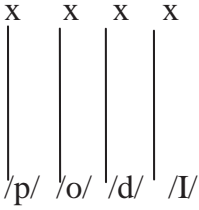

['po.dź]

Numa posterior versão da morfologia não-concatenativa, a morfologia prosódica, McCarthy (1986) ${ }^{37}$ argumenta contra moldes segmentais em favor de moldes prosódicos. Nesse aspecto, foi de grande inspiração a fonologia prosódica, outro sub-ramo da fonologia não-linear (NESPOR; VOGEL, $1986)^{38}$, que, ao abordar com mais rigor a questão dos domínios relevantes para a aplicação das regras fonológicas, propóe uma organização hierárquica de constituintes, como em (17), a seguir.

(17) $\omega$ (palavra prosódica) $\gg>\sum$ (pé) $\gg>\sigma($ sílaba $) \gg>\mu$ (mora)

A teoria da morfologia prosódica, desenvolvida em McCarthy \& Prince $(1990)^{39}$, é baseada em três principais teses:

(18) Hipótese Básica da MP: Moldes (templates) são definidos em termos de autênticas unidades da Prosódia - mora $(\mu)$, sílaba $(\sigma)$, pé $(\Sigma)$ e pala-

37 McCARTHY, J. Prosodic morphology. Amherst: University of Massachusetts and Brandeis University, 1986.

38 NESPOR, Marina; VOGEL, Irene. Prosodic Phonology. Dordrecht: Foris, 1986.

39 McCARTHY, J. \& PRINCE, A. Prosodic Morphology and Templatic Morphology. In: EID, M.; McCARTHY, J. J. (Org.). Perspectives on arabic linguistics: papers from the second symposium. Amsterdam: Benjamins. 1990, p. 1-54. 
vra fonológica $(\bowtie)$ - e constituem afirmação geral a respeito da estrutura possivel de determinados processos morfológicos (p. 98);

Condição de Satisfação ao Molde: Processos morfológicos satisfazem um molde específico que pode ser determinado tanto por princípios universais da prosódia quanto por princípios de boa-formação de línguas individuais; $\mathrm{e}$

Circunscrição Prosódica: O domínio sobre o qual determinadas operaçóes morfológicas se aplicam pode ser mapeado por primitivos prosódicos, da mesma forma que, na morfologia concatenativa, afixos se circunscrevem a domínios morfológicos como raiz, tema e palavra.

A primeira tese estabelece que o molde, na morfologia prosódica, é definido pelas categorias da hierarquia prosódica (não em termos de unidades $\mathrm{CV}$ ), o que constitui importante novidade em relação à proposta anterior. A segunda tese requer que o molde satisfaça condiçóes de boa-formação prosódica. Sob essa condição, admite-se a presença de material fonológico que seja posteriormente filtrado por um conjunto de condiçóes de boa-formação, como, por exemplo, a obrigatoriedade do constituinte onset e o licenciamento de determinados segmentos para a posição de coda silábica. A terceira tese é a central e demanda que operaçóes morfológicas sejam circunscritas por critérios prosódicos tanto quanto por expedientes morfológicos. Fundamental para a circunscrição prosódica é a funçâo de parseamento $(\mathrm{F})$, que localiza um domínio prosodicamente delimitado para aplicação de uma regra morfológica menor que a base. De acordo com McCarthy \& Prince $(1990)^{41}$, a circunscrição pode ser tanto negativa quanto positiva.

Numa circunscrição negativa, algum constituinte prosódico escaneado é dissociado e a operação morfológica aplica o material remanescente. $\mathrm{Na}$ circunscrição positiva, o constituinte prosodicamente delimitado de uma margem serve, ele mesmo, como a base de uma operação morfológica. Nesse caso, a fórmula $\mathrm{O} / \mathrm{F}(\mathrm{C}, \mathrm{M})+$ é escrita para denotar a aplicação de $\mathrm{O}$ para o constituinte $\mathrm{C}$, parseado na margem $\mathrm{M}$ por $\mathrm{F}$, que será efetivamente utilizado no processo $(+)$. 
Um dos padróes de truncamento descritos em Gonçalves \& Vazquez $(2004)^{40}$, Vazquez ${ }^{41}$ (2008) e Belchor (2009) ${ }^{42}$ e aludido em Sandmann $(1989)^{43}$ como encurtamento tipo 'refri' pode ser analisado, com os instrumentos da morfologia prosódica, por meio de uma circunscrição positiva. Nos dados em (19), a seguir, o processo de truncamento cria dissílabos oxítonos:

$$
\begin{array}{lll}
\text { refrigerante }- \text { refri } & \text { prejuízo - preju } & \text { tatuagem - tatu } \\
\text { profissional - profi } & \text { visual - visu } & \text { razoável - razu } \\
\text { bijuteria - biju } & \text { paraíba - pará } & \text { depressão - deprê }
\end{array}
$$

Numa análise pela morfologia prosódica, uma circunscrição positiva rastreia, da esquerda para a direita $(\mathrm{D} \rightarrow \mathrm{E})$, duas sílabas $(\sigma \sigma)$. O material fonológico escaneado pela circunscrição é repassado para um molde, prosodicamente definido como um iambo, isto é, como um pé binário em que a cabeça figura à direita $\left({ }^{*}\right)$. Como resultado, a operação leva a formas com acento final, isto é, a palavras sempre dissilábicas.

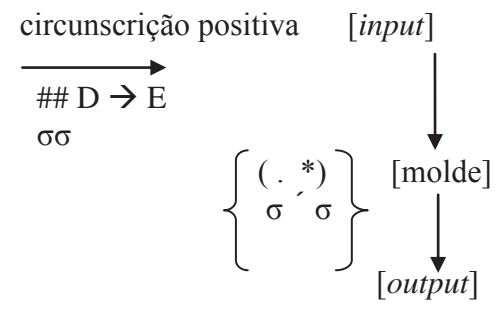

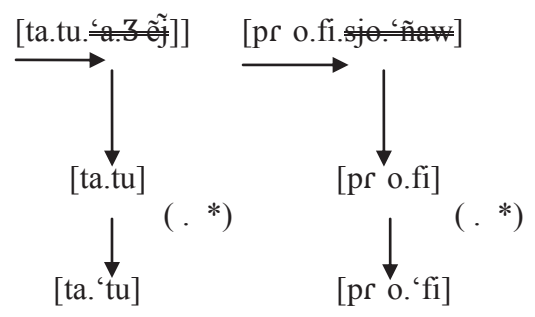

Como se vê em (21), há um nível intermediário de representação entre o input e o output, o que faz da morfologia prosódica um modelo fundamental-

40 GONÇALVES, C. A. V.; VAZQUEZ, R. P. Fla X Flu no Maraca: uma análise otimalista do truncamento no português do Brasil. In: SILVA, J. P. da. (Org.). Questöes de morfossintaxe. Volume 8. Rio de Janeiro: CiFeFil, 2004. p. 56-64.

41 VAZQUEZ, R. P. A criação lexical via formas truncadas: uma análise do fenômeno no espanhol. Rio de Janeiro: Faculdade de Letras/UFRJ, 2008.

42 BELCHOR, A. P. V. Construçôes de truncamento no português do Brasil: análise estrutural à luz da Teoria da Otimalidade. Dissertação (Mestrado em Letras Vernáculas) - UFRJ/Faculdade de Letras, Rio de Janeiro, 2009.

43 SANDMANN, A. J. Morfologia geral. São Paulo: Contexto, 1989. 
mente transderivacional (GONÇALVES, 2009) ${ }^{44}$. Por força da circunscrição prosódica, condiçóes atuam no input, gerando um output (molde), que, por sua vez, passa a ser o input sobre o qual podem atuar determinadas condiçóes de boa-formação. Uma vez satisfeitas, essas condiçôes levam à forma final (output real): o molde "[...] é a fôrma gerada pela circunscrição, mas também a forma a ser regulada pelas condições de boa-formação silábica” (GONÇALVES, 2006, p. 33) ${ }^{45}$.

Sem dúvida alguma, o modelo proposto por McCarthy \& Prince $(1990)^{46}$ consegue descrever e representar, satisfatória e elegantemente, processos morfológicos considerados, até então, "mal-comportados", "manobras difíceis, mas necessárias" ou mesmo "de difícil formalização" (GONÇALVES, 2009: 23) ${ }^{47}$. A morfologia prosódica, portanto, abre espaço para o estudo de mecanismos há muito relegados em função de seu comportamento especial, diferenciado. Uma investigação sistemática sobre a natureza desses processos tem de ser feita exatamente nessa dimensão, pois temos, aqui, exemplos concretos de como a morfologia e a fonologia se misturam de tal forma que muitas vezes é difícil decidir onde uma termina e a outra começa.

Com os recentes desenvolvimentos na teoria fonológica e, mais especificamente, a partir da emergência do tratamento das restriçóes no quadro estabelecido pela teoria da otimalidade (PRINCE \& SMOLENSKY, 1993) ${ }^{48}$, McCarthy e Prince $(1995)^{49}$ reformularam a morfologia prosódica, de modo que ela passasse a ser concebida também como uma teoria de interação de restriçốes. Há, no âmbito da otimalidade, pelo menos dois sub-modelos que lidam mais diretamente com a interface morfologia-fonologia: a teoria da correspondência (McCARTHY \& PRINCE, 1995) ${ }^{50}$, que incorpora muitos dos

${ }^{44}$ GONÇALVES, C. A. V. Introdução à morfologia não-linear. Rio de Janeiro: Publit, 2009.

45 GONÇALVES, C. A. V. Usos morfológicos. Gragoatá (UFF), v. 21, p. 219-242, 2006.

46 McCARTHY, J. \& PRINCE, A. Prosodic Morphology and Templatic Morphology. In: EID, M.; McCARTHY, J. J. (Org.). Perspectives on arabic linguistics: papers from the second symposium. Amsterdam: Benjamins. 1990, p.1-54.

47 GONÇALVES, C. A. V. Introdução à morfologia não-linear. Rio de Janeiro: Publit, 2009.

48 PRINCE, A. S.; SMOLENSKY, P. Optimality theory: constraints and interaction in Generative Grammar. Boulder: University of Colorado, 1993.

49 McCARTHY, J. J.; PRINCE, A. S. Faithfulness and reduplicative e identity. In: BECKMAN, J.; DICKEY, L.; URBANCZYK S. (Org.). University of Massachusetts Occasional Papers in Linguistics 18: Papers in Optimality Theory. Amherst: GLSA, 1995. p.333-379. 
achados da morfologia prosódica, e TO estratal (KIPARSKY, 1997) ${ }^{50}$, que abandona o princípio do paralelismo e com isso prevê, como na fonologia lexical, estratos ordenados na descrição de fenômenos morfo-fonológicos. Isso, no entanto, é assunto para outro paper.

\title{
PHONOLOGY-MORPHOLOGY INTERFACE: THEORIES, APPROACHES AND THEMES
}

\begin{abstract}
In this paper, we describe the theoretical models for the treatment of the morphology-phonology interface in contemporary linguistics until the advent of optimality theory (in the early 1990's). By focusing on the difference between uni and bilateral proposals to the treatment of these two levels, we present some phenomena of Portuguese that can be described in this perspective.
\end{abstract}

KEYWORDS: morphology, phonology; interface.

Recebido em: 20/03/2013

Aprovado em: 20/20/2013

50 KIPARSKY, P. Lexical Phonology \& Morphology. Iceland: Scancinavian Summer School in Generative Phonology, 1997. 